\title{
Discussion Papers
}

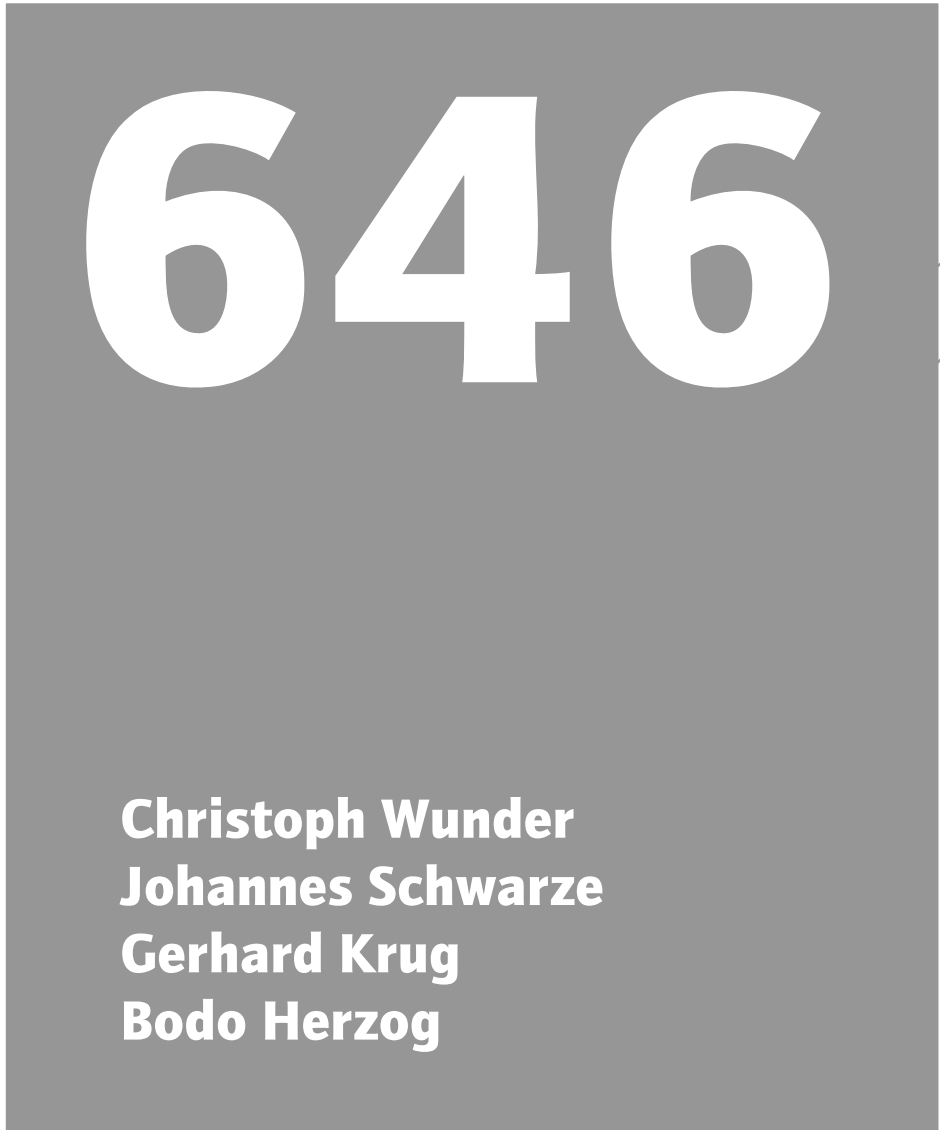

Christoph Wunder Johannes Schwarze Gerhard Krug Bodo Herzog

\section{DIW Berlin}

Welfare Effects of the Euro Cash Changeover

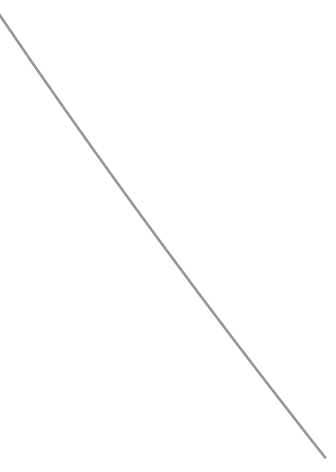

Berlin, November 2006 



\title{
Welfare Effects of the Euro Cash Changeover
}

\author{
Christoph Wunder \\ University of Bamberg \\ Gerhard Krug \\ Institute for Employment Research \\ of the Federal Employment Services
}

\author{
Johannes Schwarze \\ University of Bamberg, \\ DIW Berlin and IZA Bonn \\ Bodo Herzog \\ German Council of Economic Experts
}

$11 / 2006$

\begin{abstract}
Using merged data from the British Household Panel Survey (BHPS) and the German SocioEconomic Panel (SOEP), this paper applies a parametric difference-in-differences approach to assess the real effects of the introduction of the euro on subjective well-being. A complementary nonparametric approach is also used to analyze the impact of difficulties with the new currency on well-being. The results indicate a severe loss in well-being associated with the introduction of the new currency, with the predicted probability that a person is contented with his/her household income diminishing by 9.7 percentage points. We calculate a compensating income variation of approximately one-third. That is, an increase in postgovernment household income of more than $30 \%$ is needed to compensate for the rather drastic decline in well-being. The reasons for the negative impact are threefold. First, perceived inflation overestimates the real increase in prices resulting in suboptimal consumption decisions. Second, money illusion causes a false assessment of the budget constraint. Third, individuals have to bear the costs from the conversion and the adjustment to the new currency. Moreover, it is thought that losses are smaller when financial ability is higher. However, the impact of difficulties in using and converting the new currency is rather small, and the initial problems were overcome within one year of the introduction of euro cash.
\end{abstract}

Keywords: subjective well-being, euro cash changeover, perceived inflation, difference-indifferences

JEL Classification: E31, I31

Corresponding author:

Christoph Wunder

University of Bamberg

Department of Economics

Feldkirchenstraße 21

D-96045 Bamberg

E-Mail: christoph.wunder@ sowi.uni-bamberg.de

Acknowledgments: We would like to thank Jens Härpfer and Sara Kleyer for their assistance with the datasets used in this paper. 
Opinions expressed in this paper are those of the author and do not necessarily reflect views of the institute.

\section{IMPRESSUM}

(C) DIW Berlin, 2006

DIW Berlin

German Institute for Economic Research

Königin-Luise-Str. 5

14195 Berlin

Tel. +49 (30) $89789-0$

Fax +49 (30) $89789-200$

http://www.diw.de

ISSN print edition 1433-0210

ISSN electronic edition 1619-4535

Available for free downloading from the DIW Berlin website. 


\section{Introduction}

Although official statistics provide no evidence for atypical inflation rates, several studies have established that individuals perceived substantial increases in prices attributed to the euro cash changeover (cf. e.g., Brachinger 2006; Stix 2005). This raises the question whether higher perceived inflation and other psychological phenomena related to the introduction of the euro had real effects on individual well-being. Among other things, such real effects may evolve for three reasons. First, if consumers overestimate inflation, they underestimate their purchasing power. The false assessment of consumption possibilities leads to suboptimal consumption decisions and a lower level of individual well-being. Secondly, the subjective value of income decreases if the payment in a new currency results in money illusion. As the deutschmark-euro exchange rate suggested the halving of nominal income, this could have led to a tightening of the budget constraints self-assessed by individuals. Third, people had to bear the costs of the changeover and adjustment to the euro and the loss of the older trusted currency, in the form of the deutschmark (DM).

This paper presents the first approach to analyzing the effect on individual well-being of the replacement of the deutschmark by the euro. Using data from the German Socio-Economic Panel (SOEP) and the British Household Panel Survey (BHPS), we evaluate the impact of the introduction of euro cash on satisfaction with income. As in many other studies, (for an overview cf. e.g., Frey and Stutzer 2002a) satisfaction with income can be interpreted as a direct measure of subjective well-being. Using a difference-in-differences approach, we estimate a common model for Germany and Great Britain in which the introduction of the euro can be considered as a treatment effect. The British population serves as the control group, because the euro has yet to be introduced in Great Britain. The results from the difference-in-differences estimations indicate a clear negative impact on financial satisfaction because of the new currency. We found that the causal effect led to a drastic decline in the predicted probability that a person is contented with his/her household income of about 9.7 percentage points. A compensation for this severe loss in well-being would then require an increase in household income of approximately one-third.

Further investigation of the impact of financial ability on the process of the changeover to the new currency provides additional insights. Financial ability is operationalized by identifying 
persons who reported difficulties in converting the old to the new currency. We find that the initial problems with the euro had been overcome within one year of its introduction.

The paper is organized as follows. In Section 2, we discuss three possible influences of the introduction of the euro on individuals' financial contentment. The central hypotheses and methodology are also developed. Sections 3 and 4 describe the data and the econometric strategy, respectively. The empirical results are presented in Section 5. Section 6 concludes the main body of the paper.

\section{The impact of introduction of the euro on subjective well-being}

Following the introduction of euro cash on 1 January 2002, the perception of strong increases in prices was a much discussed topic in nearly the entire euro area. Public opinion polls showed that euro-area citizens believed that the introduction of euro cash would cause price rises. Over 93\% held this opinion according to a recent survey from the European Commission. Brachinger (2006) for Germany and Fluch and Stix (2005) for Austria established in detailed studies that perceptions of price increases can be observed, even when other variables are controlled for. However, official statistics showed that average price inflation remained fairly constant during the introduction of the euro. Indeed, only $0.09 \%$ to $0.28 \%$ at most of the observed $2.3 \%$ price inflation could be attributed to the euro, while unrelated factors, such as new tobacco taxes, extra travel security costs following 9/11, the impact of bad weather on fruit and vegetables prices, and high energy prices, all contributed to "normal" inflation. The Deutsche Bundesbank concluded that the introduction of the euro did not have a major impact on the cost of living as a whole (cf. Deutsche Bundesbank 2002). Significantly, inflation rates outside the euro area, such as in Denmark and the United Kingdom, showed similar behavior for similar sorts of reasons (cf. European Commission 2006a).

This apparent gap between the actual inflation rate and the perception of inflation must be seen as a first reason for a possible loss in financial satisfaction because of the introduction of the new currency. The reasons for this gap are twofold. First of all, sectoral studies show a "grey zone" of consumer goods and services that did indicate unexplained price rises during the euro changeover. Most of these were in the service sector, including restaurants and cafés, hairdressers, and repair and cleaning services. Notably, these are sectors with relatively little competition—small local shops rather than large retailers-and they are for everyday goods 
and services that people purchase frequently but that form only a minor portion of the cost of living. Many national studies confirmed large price increases in these sectors, particularly in the period 1996 to 2005, when prices for durable goods remained either stable or fell. A second explanation is a subjective approach to consumer behavior. The psychological observation is that price increases are noticed more than decreases, and the fact that consumers tend to compare 2006 prices with the price in national currency in 2001. This approach appears potentially fruitful in explaining the large and persistent perception gap and its origin.

If inflation or, equivalently, the prices of consumption goods are overestimated, the subjective perception of purchasing power decreases. Thus, the individual is less contented with income when household income remains constant. In addition, the subjective value of a given income may be valued less when it is changed into euros if the euro is associated with higher inflation rates.

A second reason for the decline in well-being may have evolved from the change in the nominal value of incomes. The tendency to value economic transactions in nominal, rather than real, terms is called money illusion (cf. Fisher 1928). In principle, the actual value of income can be assessed in either nominal or real terms. Shafir et al. (1997) propose that a nominal representation of income is a common phenomenon because the nominal value is a salient and natural unit of money. In view of the fact that most units of measurement do not change (for example, the meter-kilogram-second systems of units), the introduction of a new currencyand with it a new unit of measurement-represented a deep intervention in the usual frame of economic reference. However, the evaluation of the true value of income is feasible only with reference to the real representation. In reality, people expect to evaluate their income in accordance with neither a purely nominal nor a purely real representation. Instead, they are supposed to make use of a mixture of both concepts. This behavior induces, as a consequence, a bias in the evaluation of the actual value of income.

The reference to nominal terms also applies to the assessment of prices. However, Shafir et al. (1997) provided evidence that people are particularly averse to nominal cuts in earnings. It is proposed, therefore, that the impact on incomes overcompensates for the impact on prices. In addition, and as argued earlier, the perception of disguised increases appears to dominate people's opinions on prices. 
The introduction of the euro induced a clear change in the nominal income in Germany. The DM-euro exchange rate of 1.95583 was bound to give the impression that incomes were halved. If people evaluate their earnings referring to nominal terms, they then underestimate their real purchasing power, thereby experiencing a tightening of the budget constraint that did not actually occur. In a simple microeconomic framework of the optimal household consumption decision, the perceived budget restriction shifts inwards, and thus well-being declines. Following the view that people evaluate their earnings with reference to nominal representations, we conclude that well-being is strongly affected by the nominal change in incomes induced by the measurement in the new currency, even in the absence of real changes.

Aside from these effects caused by the perception of inflation and the changes in nominal incomes, the substitution of an international for a national money system could have had a third impact on people's well-being. The changeover to euro cash was accompanied with costs resulting from, e.g., the conversion and adjustment to the new measurement unit. People may have a different attitude towards the euro compared with the old national currency. Attitudes may also influence the perception of monetary transactions and the way they are carried out. Comparing different amounts of money, Brandstätter and Brandstätter (1996), for example, found that the subjective value of money was influenced by people's attitudes towards money, and Ostaszewski et al. (1998) ascertained for Poland that the subjective value of reward was less when its amount was specified in old zlotys, which were associated with higher inflation rates, than when it was specified in dollars. These findings show that the attractiveness of money is influenced by people's attitudes towards the currency.

As the points discussed indicate, there are possible economic and psychological modes of action that lead to changes in the perception and estimation of prices and earnings caused by the introduction of the euro. Whereas some of these processes are triggered by the pure change in nominal values (money illusion), others are based on people's perception of inflation, as well as the costs of adjustment and the attitudes towards the new currency. Thus, the question arises whether and to what extent these issues have real effects on individuals' welfare.

To investigate the possible real effects of the introduction of the euro on individuals' wellbeing, we use a direct measure of subjective well-being: satisfaction with household income. Thus, our approach is based on recent literature in empirical welfare economics, where survey questions on happiness or satisfaction are interpreted as an operational proxy measure for 
individual preferences, subjective well-being, and respective utility (cf. e.g., Frey and Stutzer 2002b; Layard 2005). Satisfaction data have been used to analyze, among others, labor market issues (cf. e.g., Clark and Oswald 1994; Winkelmann and Winkelmann 1998), public-choice related issues (cf. e.g., Frey and Stutzer 2000), income and well-being (cf. e.g., Schwarze 2003). If there are any real effects on well-being, income satisfaction is expected to decline because of the introduction of the euro. Moreover, satisfaction with income can capture several of the effects described above.

How can one draw a conclusion about the impact of the introduction of the euro on the German people? We apply parametric as well as nonparametric difference-in-differences approaches-econometric estimation strategies from the field of policy evaluation-to identify the effect of the changeover to the euro on income satisfaction. Merging data from the German Socio-Economic Panel (SOEP) and the British Household Panel Survey (BHPS), a treatment group and a control group is made available. The German population serves as the treatment group and the British population represents the control group. This is because euro cash has not yet been introduced in Great Britain. However, this method requires the assumption that there were neither other policy measures nor further reasons that systematically influenced financial contentment. This assumption seems to be very strong, but who would deny that the introduction of the euro was the most extensive single event of the period under consideration? Therefore, it appears plausible to ascribe the cause for the change in financial contentment, to a great extent, to the new currency.

\section{Data}

Combining data from two rich micro-datasets, the German Socio-Economic Panel (SOEP) and the British Household Panel Survey (BHPS), a German treatment group that is affected by the introduction of euro cash and a British control group was generated. This paper makes use of the 2001 and 2003 waves, the years before and after the introduction of the euro, respectively. Both, the SOEP and the BHPS, are representative longitudinal studies of private households in which the same persons are surveyed every year. The SOEP began in 1984 with 5,921 households containing a total of 12,290 individuals (cf. Haisken-DeNew and Frick 2005). It was extended several times-e.g., the population of Eastern Germany was included as early as 1990 - and refreshment samples were added to cope with panel attrition and mortality in 
subsequent years. ${ }^{1}$ The BHPS started in 1991 with 5,500 households and 10,300 individuals. Since 2001, the sample has covered all areas of Great Britain. Taylor et al. (2006) provided detailed information about the survey.

A joint dataset that merges information from different sources must guarantee that the variables used are comparable. This condition is fulfilled in the present case as argued in the following key points. First, considering the household size, education (with respect to high school) and, in particular, the postgovernment household income, the data are extracted from the respective Cross-National Equivalent Files (CNEF) of the BHPS and SOEP (cf. Burkhauser et al. 2000). The CNEF database ensures that the variables from the national datasets are defined equivalently. In addition, it is possible to link this information directly to the original surveys. Second, as the variables on the person's characteristics, e.g., marital, job and health status, are defined in the same way in the BHPS and SOEP, it is possible to combine this information. Third, we ensured the comparability of satisfaction with the household income using the procedure described in the next paragraph.

As the datasets apply satisfaction scales that differ in the number of categories- the SOEP uses an 11-point scale while the BHPS has a seven-point scale-both scales were dichotomized to make the information more comparable. The following assumption about the dummy variable identifying the satisfied persons was made. The respondents in the BHPS are regarded as contented with their household income if they reported values of 5, 6 or 7 on a seven-point scale. For respondents in the SOEP, the corresponding values are 7, 8, 9 or 10 on an 11-point scale. This procedure is equivalent to dichotomizing at the respective averages of satisfaction.

The detailed distribution of satisfaction with the household income in Great Britain and Germany can be found in figure 1 for each year. The shifts in the distribution of the two countries indicates that the development of financial satisfaction moved in opposite directions. On the basis of the dichotomization, $53 \%$ of the respondents of the BHPS can be considered as con-

\footnotetext{
${ }^{1}$ The data from the SOEP used in this paper was extracted from the SOEP Database provided by the DIW Berlin (http://www.diw.de/soep) using the Add-On package SOEP Menu v2.0 (Jul 2005) for Stata(R). SOEP Menu was written by Dr. John P. Haisken-DeNew (john@soepmenu.de). The following authors supplied SOEP Menu Plug-ins used to ensure longitudinal consistency, John P. Haisken-DeNew - h3111x p2282x p2291x p2297x p3468x p3483x p488x p622x p83x p90x , Markus Hahn and John P. Haisken-DeNew (GENERATED) - p3470x p4184x p4186x. The SOEP Menu generated DO file to retrieve the SOEP data used here and any SOEP Menu Plug-ins are available upon request. Any data or computational errors in this paper are our own. Haisken-DeNew (2005) describes SOEP Menu in detail.
} 


\section{Figure 1}

\section{Distribution of satisfaction with household income}

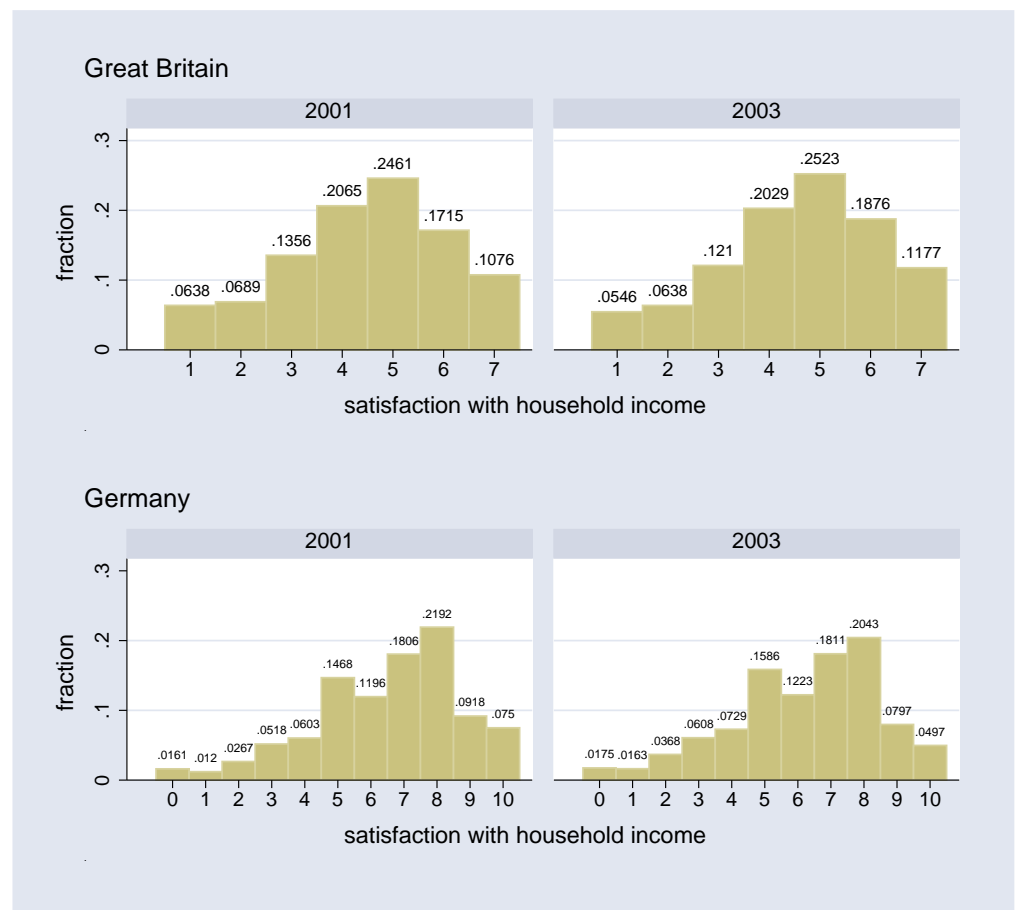

Source: SOEP and BHPS, 2001 and 2003.

tented in 2001. This portion increases to $57 \%$ two years later. The situation in Germany is the opposite because a decline in satisfaction can be discerned. While the portion of people who report themselves as contented is about $57 \%$ in 2001 , the number decreases to $52 \%$ after the introduction of the euro.

\section{Estimation strategies}

\subsection{A parametric difference-in-differences estimator}

Applying a parametric difference-in-differences (DID) estimator, we capture the changes in satisfaction with the household income from 2001 to 2003 because of the introduction of the euro. This econometric model assumes that the latent satisfaction $y_{r i t}^{*}$ of the $i$-th individual in region $r$ at time $t$ depends on the currency as well as on further covariates as follows.

$$
y_{\text {rit }}^{*}=\beta_{0}+\beta_{1} \text { euro }_{\text {rit }}+\beta_{2} \text { time }_{\text {rit }}+\beta_{\text {DID }}(\text { euro } \cdot \text { time })_{\text {rit }}+\mathbf{x}_{\text {rit }}^{\prime} \beta+\mathbf{z}_{r t}^{\prime} \gamma+\eta_{\text {rit }}
$$


The variable EURO is a dummy variable that identifies the German part of the sample, i.e., the SOEP respondents. As they are the ones who are affected by the new currency, the SOEP (sub)population can, in the context of evaluating the impact of the introduction of the euro, be regarded as the treatment group. The corresponding coefficient $\beta_{1}$ measures the time-invariant differences between the treatment and the control group. The variable TIME is also a dummy variable indicating the period after the introduction of the euro. $\beta_{2}$ provides, therefore, information about the common time trend in satisfaction in the treatment and control groups. That is, the DID approach allows us to control the common time trend that affects the people in Great Britain and, simultaneously, in Germany-two economies highly involved in global trade. The parameter on the interaction term, $\beta_{D I D}$, is the main topic of the evaluation. $\beta_{D I D}$ captures the change in the latent satisfaction with the household income that results from the introduction of the euro. In the case of a linear model, the estimator of $\beta_{D I D}$ is interpreted as the causal effect of a policy.

This paper takes also into account the fact that well-being depends not only on variables at the micro level included in the vector $\mathbf{x}$ but also on the macro variables of the economic environment given in the vector $\mathbf{z}$. Accordingly, financial contentment may be affected by the regional economic conditions where the individuals live. In particular, the model controls for the unemployment rate, economic growth and inflation-all measured at the regional level, i.e., the NUTS 1-equivalent level. ${ }^{2}$ The macro variables vary only between regions at time $t$ and are constant for every individual within the regional cluster. Moulton (1990) pointed out that merging macro variables with micro data can lead to incorrect standard errors because the assumption of independent errors is not appropriate for clustered data. The dependency of the micro units within the same regional cluster arises from the fact that not all macro variables that have an impact on the satisfaction with the household income can be observed. This paper uses a nested error component structure to control for the cluster-specific unobserved heterogeneity on the regional and the individual level. The error term of equation 1 can therefore be written as

$$
\eta_{r i t}=\mu_{r}+v_{r i}+\varepsilon_{r i t}
$$

\footnotetext{
${ }^{2}$ The macro variables are from Eurostat and the Croner-Reward Group.
} 
where $\mu_{r}$ captures the time-invariant regional specific effects and $v_{r i}$ controls for the individual specific effects. It is assumed that $\mu_{r} \sim \mathrm{N}\left(0, \sigma_{\mu}^{2}\right)$ and $v_{r i} \sim \mathrm{N}\left(0, \sigma_{v}^{2}\right)$. $\varepsilon_{r i t}$ is the idiosyncratic error term.

The left-hand-side variable $y_{\text {rit }}^{*}$ of equation 1 represents the unobserved financial satisfaction. This latent variable is related to the generated binary response $y_{\text {rit }}$ through a threshold concept. The observed response $y_{\text {rit }}$ indicates whether the $i$-th individual in region $r$ is satisfied with his/her household income at time $t$ or not. The exact definition of $y_{\text {rit }}$ is given in the previous section. $\varepsilon_{r i t}$ is assumed to be logistically distributed. Consequently, the model can be written as

$$
E\left(y_{\text {rit }}\right)=\Lambda\left(\beta_{0}+\beta_{1} \text { euro }_{\text {rit }}+\beta_{2} \text { time }_{\text {rit }}+\beta_{\text {DID }}(\text { euro } \cdot \text { time })_{\text {rit }}+\mathbf{x}_{\text {rit }}^{\prime} \beta+\mathbf{z}_{r t}^{\prime} \gamma+\mu_{r}+v_{r i}\right)
$$

where $\Lambda(\cdot)$ denotes the logistic cumulative distribution. For the sake of simplicity and better readability, we refer only to the individual characteristics in the vector $\mathbf{x}$ and the corresponding coefficient vector $\beta$ in the remainder of this section. Among others, Gibbons and Hedeker (1997), Guo and Zhao (2000) and Skrondal and Rabe-Hasketh (2004) have provided overviews of the application of a logistic regression framework to a model with a nested error component structure.

The first important consequence from the application of a logit model is that - in contrast to the linear model - the treatment effect is not equal to the marginal effect of the interaction term (cf. Ai and Norton 2003). In the logit specification, the interaction effect must be calculated as the cross partial derivative. For the case of two dummy variables, Norton et al. (2004) showed that it simplifies to

$$
\frac{\Delta^{2} \Lambda(\cdot)}{\Delta \text { euro } \Delta \text { time }}=\frac{1}{1+e^{-\left(\beta_{1}+\beta_{2}+\beta_{D I D}+\mathbf{x}^{\prime} \beta\right)}}-\frac{1}{1+e^{-\left(\beta_{1}+\mathbf{x}^{\prime} \beta\right)}}-\frac{1}{1+e^{-\left(\beta_{2}+\mathbf{x}^{\prime} \beta\right)}}+\frac{1}{1+e^{-\mathbf{x}^{\prime} \beta}}
$$

Equation 4 makes clear that the magnitude of the causal effect depends on the values of the independent variables in the vector $\mathbf{x}$. Instead of considering the contribution of each covariate, Mitchell and Chen (2005) propose the calculation of the aggregate contribution of all variables, the covariate contribution. The paper refers to this concept when the predicted probabilities are visualized for the treatment and the control group. 
The second consequence concerns the statistical significance of the treatment effect. This cannot be determined on the basis of a t-test of the parameter $\hat{\beta}_{D I D}$. Instead, Ai and Norton (2003) suggest the computation of the standard error of the DID estimator with the Delta method. The asymptotic variance of $\hat{\beta}_{D I D}$ is therefore

$$
\hat{\sigma}_{D I D}^{2}=\frac{\partial\left[\frac{\Delta^{2} \Lambda(\cdot)}{\Delta \text { euro } \Delta \text { time }}\right]}{\partial \beta^{\prime}} \hat{\Omega}_{\beta} \frac{\partial\left[\frac{\Delta^{2} \Lambda(\cdot)}{\Delta \text { euro } \Delta \text { time }}\right]}{\partial \beta}
$$

where $\hat{\Omega}_{\beta}$ denotes a consistent estimator of the variance-covariance matrix of the coefficient vector $\beta$. Using $\hat{\sigma}_{D I D}^{2}$, a simple t-test is appropriate to assess the statistical significance of the treatment effect. From equation 5, it follows that not only do the values of the DID estimator depend on the covariates, but also its variance is conditional on the independent variables. Thus, the result from the t-test of the statistical significance is only valid for the specific values of $\mathbf{x}$. In this paper, the t-test is conducted only for the sample averages, i.e., for the values of $\overline{\mathbf{x}}$, so that

$$
\frac{\partial\left[\frac{\Delta^{2} \Lambda(\cdot)}{\Delta \text { euro } \Delta \text { time }}\right]}{\partial \beta}=\left[\begin{array}{c}
\left(\phi_{11}-\phi_{01}\right)-\left(\phi_{10}-\phi_{00}\right) \\
\phi_{11}-\phi_{10} \\
\phi_{11}-\phi_{01} \\
\phi_{11} \\
{\left[\left(\phi_{11}-\phi_{01}\right)-\left(\phi_{10}-\phi_{00}\right)\right] \cdot \overline{\mathbf{x}}}
\end{array}\right]_{(K \times 1)}
$$

with

$$
\begin{aligned}
& \phi_{11}=P(y=1 \mid \text { euro }=1, \text { time }=1) \cdot[1-P(y=1 \mid \text { euro }=1, \text { time }=1)] \\
& \phi_{10}=P(y=1 \mid \text { euro }=1, \text { time }=0) \cdot[1-P(y=1 \mid \text { euro }=1, \text { time }=0)] \\
& \phi_{01}=P(y=1 \mid \text { euro }=0, \text { time }=1) \cdot[1-P(y=1 \mid \text { euro }=0, \text { time }=1)] \\
& \phi_{00}=P(y=1 \mid \text { euro }=0, \text { time }=0) \cdot[1-P(y=1 \mid \text { euro }=0, \text { time }=0)] .
\end{aligned}
$$




\subsection{Nonparametric difference-in-differences estimator}

In addition to the parametric DID estimator, we use a nonparametric DID matching estimator to discern whether the loss in welfare through introduction of euro cash can - at least in partbe attributed to difficulties in handling the conversion from the DM to the euro (cf. Heckman et al. 1998; Smith and Todd 2005). The causal parameter to be estimated is called the average treatment effect on the treated. This measures the effect of a treatment by comparing the actual mean outcomes of individuals receiving treatment (i.e., problems in converting DM to euro) with the counterfactual mean outcomes in the hypothetical situation of no treatment (i.e., no problems with the new currency). It must be emphasized that in applying this approach, we limit the analysis to the German subsample and consider-in contrast to the parametric DID estimation strategy - a person's difficulties in converting DM to euro as the treatment. The causal effect to be estimated is

$$
\delta_{D I D}(\mathbf{s})=E\left(y_{1}^{1}-y_{0}^{0} \mid \mathbf{s}, e=1\right)-E\left(y_{1}^{0}-y_{0}^{0} \mid \mathbf{s}, e=1\right)
$$

where $e$ denotes the treatment status, the superscript denotes whether the outcome is realized under the treatment (1) or the control (0) situation, and the subscript denotes time. Normally, the counterfactual situation is achieved by conditioning on a set $\mathrm{s}$ of covariates to the treatment participation and outcome in a regression. In contrast, the matching approach does this by matching one (or more) individuals $j$ to each of the individuals $i$ in the treatment group. Except for differences in treatment status, $j$ and $i$ have to have identical values in $\mathbf{s}$ or, as Rosenbaum and Rubin (1983) have shown, similar propensity scores (PS) so that

$$
\delta_{D I D}(P(\mathbf{s}))=E\left(y_{1}^{1}-y_{0}^{0} \mid P(\mathbf{s}), e=1\right)-E\left(y_{1}^{0}-y_{0}^{0} \mid P(\mathbf{s}), e=1\right)
$$

where $P(\mathbf{s})=\operatorname{Pr}(e=1 \mid \mathbf{s})$ is the probability of receiving treatment conditional on the values of s, usually estimated using logit or probit binary choice models.

One major problem with matching is that all variables in $\mathbf{s}$ have to be measured and built into constructing the propensity score. By taking the outcome of interest to be the difference in the outcome variable at two points in time, Heckman et al. (1998) extended the matching approach to situations where not all $\mathbf{s}$ are observed but only a subset $\mathbf{x}$. The remaining variables 
are allowed to be unobserved and unspecified, so long as their influence remains constant over time. The key identifying assumption of the DID matching estimator is

$$
E\left(y_{1}^{0}-y_{0}^{0} \mid P(\mathbf{x}), e=1\right)=E\left(y_{1}^{0}-y_{0}^{0} \mid P(\mathbf{x}), e=0\right)
$$

meaning that conditional on the probability of receiving treatment (given covariates $\mathbf{x}$ ) before and after differences in outcome are conditional mean independent of treatment status. Under this condition, the counterfactual mean outcome of the treatment group can be estimated using the mean outcome in (a subpopulation of) the control group.

The DID matching estimator is given by (cf. Smith and Todd 2005; Blundell and Costa Dias 2002; Bergemann et al. 2005):

$$
\hat{\delta}_{D I D}=\frac{1}{n_{1}} \sum_{i \in I_{1} \cap C S}\left(\left(y_{1 i}^{1}-y_{0 i}^{0}\right)-\sum_{j \in I_{0} \cap C S} w(i, j)\left(y_{1 j}^{0}-y_{0 j}^{0}\right)\right)
$$

with CS denoting the region of common support, and $I_{1}$ and $I_{0}$ denoting treatment and control groups, respectively. $n_{1}$ is the number of individuals of the treatment group satisfying the common support condition, and $w(i, j)$ is the weight given to observation $j$ when matched to observation $i$. Depending on the choice of $w(i, j)$, different versions of the matching estimators can be constructed. For example, in single-nearest neighbor (SNNM) matching without replacement, observation $j$ is chosen as a match to observation $i$, when it is closest to $i$ in terms of the absolute distance of their propensity scores $\left|P(\mathbf{s})_{i}-P(\mathbf{s})_{j}\right|$.

To avoid matches where $P(\mathbf{s})_{j}$ even though being the nearest neighbor to $P(\mathbf{s})_{i}$ is very far from it, a maximum level of acceptable distances (caliper) has to be set. SNNM then weighs the outcome of the observation $j$ whose propensity score is closest to observation $i$ 's propensity score with $w(i, j)=1$ and all other control observations with $w(i, j)=0$ and computes the causal effect. When more than one control observation is used, as with multiple-nearest neighbor matching (MNNM), the counterfactual is constructed as a weighted mean of the matched controls. Below, we use MNNM with a maximum of 3 controls and a caliper of 0.0005 . 


\section{Results}

\subsection{Opinions on the euro}

In 2002, the SOEP ascertained satisfaction with the euro with the following question: "All in all, how satisfied are you with the introduction of the euro?" (Schupp and Wagner 2007). The respondents responded on an 11-point scale ( 0 is completely dissatisfied and 10 is completely satisfied). Figure 2 shows the temporal development of satisfaction with the euro. The figure makes use of the fact that the SOEP interviews were temporally distributed from January to November. However, October and November were excluded from the analysis because there are only seven and two interviews, respectively. Although more than $75 \%$ of the interviews were conducted in the first three months of the year, the months April to September still provide a sufficient number of cases to compute meaningful averages of satisfaction with the euro. A possible shortcoming of using the monthly averages is that the monthly subsamples are affected by a selection bias (cf. Dittmann 2005). Respondents who can easily be contacted (for example, elderly persons) are over-represented at the beginning of the year and under-represented in the later course of the year. However, we suppose that the selective subsamples do not present a distorted picture of the temporal development of the contentment with the euro.

From this illustration, it follows that satisfaction with the new currency decreased during the months following the introduction of euro cash (the solid curve). Evidently, contentment with the euro exhibited its largest value of almost 6.0 in January 2002. In the course of the year, the values clearly decrease. It is supposed that first experiences with the euro led to rising skepticism towards the new currency. The lower satisfaction values occurring in the second half of the year lie twice under the 5.0 mark. These findings point to the fact that the euro did not fully come up to peoples' expectations. Possibly, the clear decline in satisfaction also reflects the perceived increase in prices for which the euro was made responsible.

We use data from the consumer survey (cf. European Commission 2006b) to assess how the development of prices was felt by the people. The dashed-dotted line referring to the second $y$-axis in figure 2 illustrates the differences between the proportion of persons who have the opinion that the prices have risen a lot or moderately, and the proportion of persons who think that prices have stayed about the same or fallen. The higher the number, the greater the pro- 
portion of people who perceived an increase in prices. A drastic increase, especially in the first three months of 2002, is observed, which may affect contentment with the new currency.

In addition, the figure includes an illustration of the temporal development of satisfaction with household income in 2002 and the previous year (2001). Obviously, the dashed curve for 2002 has a similar profile to the development of the satisfaction with the introduction of the euro. In particular, the downward movement in the second half of the year mirrors the decline in the contentment with the euro. The correlation coefficient of 0.75 indicates a clear positive relationship between the monthly averages. Conversely, the monthly development of the satisfaction in 2001 (dotted curve), the year before the euro was introduced, does not exhibit such a temporal negative trend throughout the year.

\section{Figure 2}

Satisfaction with the introduction of the euro and the household income

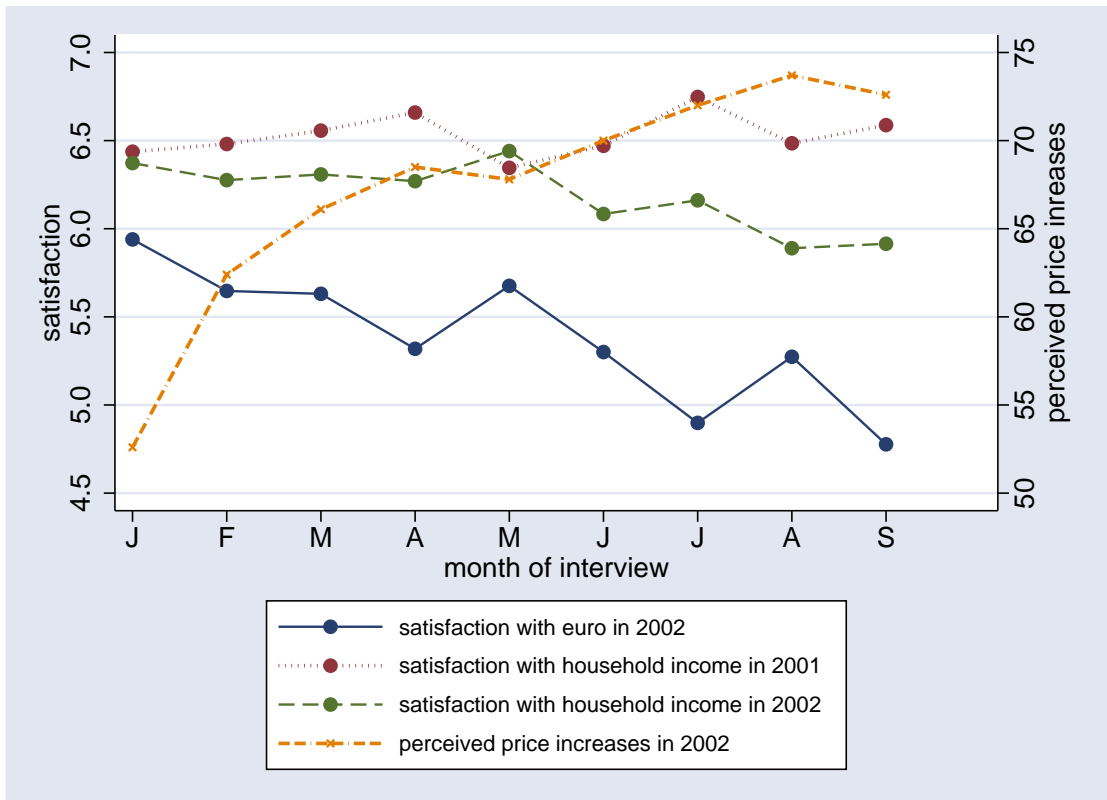

Source: SOEP 2001, 2002, cross-section weighted. Consumer survey 2002.

In addition, the SOEP recorded the respondents' opinions on the euro with several questions in 2002. Figure 3 provides an overview. The numbers report an ambiguous atmosphere ranging between weak optimism and some skepticism.

A rather optimistic view finds its expression in the $70 \%$ of respondents who said that the euro promotes European unity (categories "more likely to apply" and "completely applies" are added). Even so, $10 \%$ of the population have serious doubts about this issue. They consider the common currency as not beneficial for the merging of the countries. However, the people have 
a less optimistic attitude towards the euro with respect to the question whether the new currency will make private investment more unstable. Judging this issue, a mere $60 \%$ respond that the stability of investments is unaffected.

Public opinion appears to be divided with respect to the following question. The respondents seem uncertain whether they could expect to derive advantage from the euro: half of all respondents have an expectation of an economic advantage and half do not. In addition, people do not clearly commit themselves to one direction in the answer, but instead prefer to respond "more likely".

A more cautious, pessimistic view appears when the move from the DM with respect to the associated disadvantages is considered: $56 \%$ of people are afraid that the scrapping of the DM will lead to some difficulties. In this context, a narrow majority of 54\% laments the passing of the DM. In view of the fact that the DM was a trusted currency, not only in Germany but elsewhere, this appears to reflect only a little disinclination for the euro. Rather, the reserved attitude may be a result of uncertainty with the development of the new currency.

\section{Figure 3}

\section{Opinions on the euro}
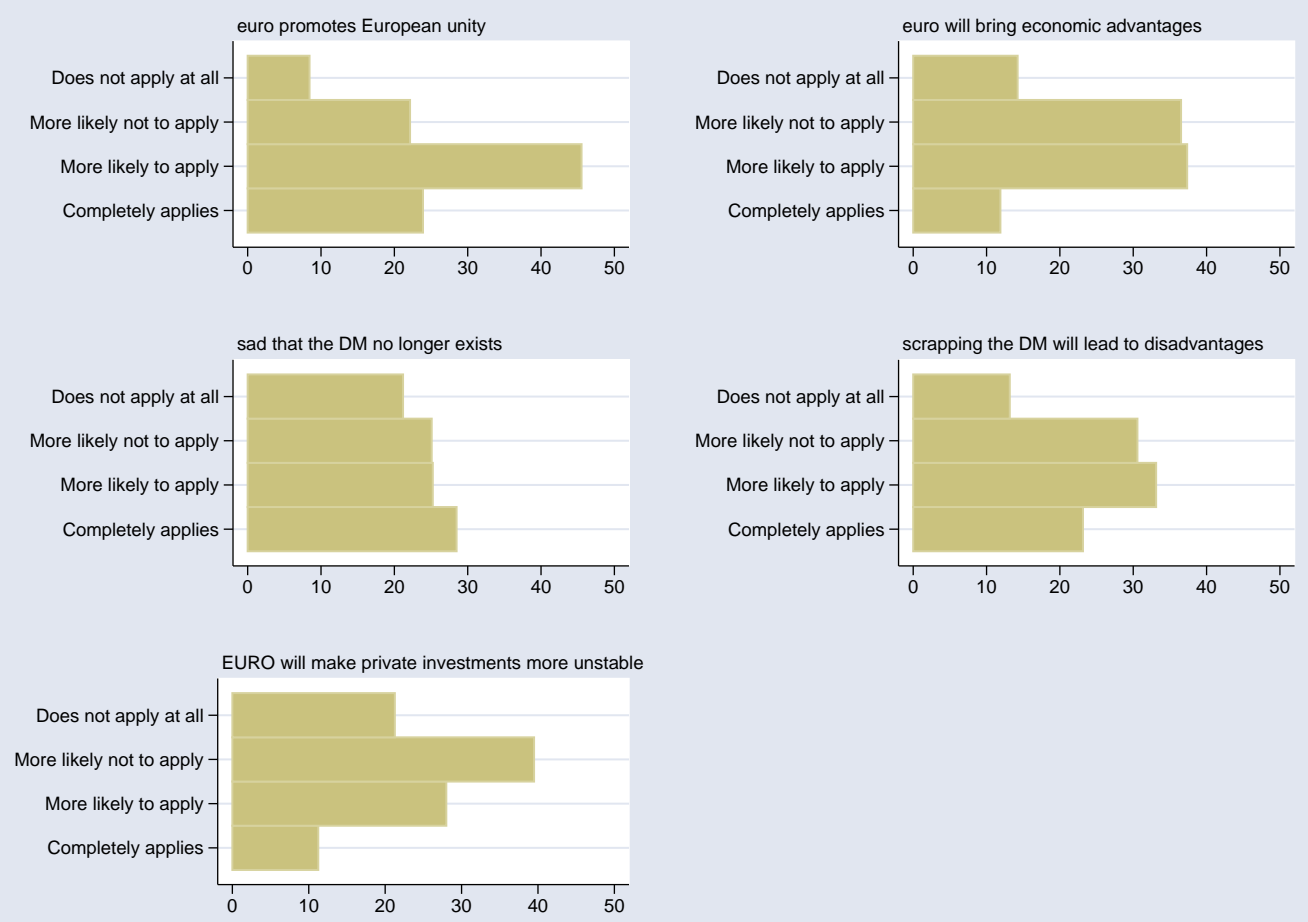

Source: SOEP 2002, cross-section weighted, in percentage points. 
In sum, opinions on the euro are split. Although positive expectations associated with the new currency regarding the growing together of the European Union can be diagnosed, there is also clear evidence of some skepticism. The analysis suggests that the latter is mainly because of the loss of the old currency in the form of the DM. A more detailed investigation of the attitudes towards the euro was carried out by Isengard and Schneider (2006).

\subsection{The euro and financial contentment in Great Britain and Germany}

Table 1 (columns 3 and 4) shows the estimation results of the econometric model introduced above. The estimates are used for calculating the predicted probability that a person is contented with his/her household income. The predicted probabilities are computed separately for the British and Germans before and after the introduction of the euro. In a nonlinear model, the predicted probabilities are not constant but depend on the values of the covariates. Figure 4 illustrates.

It is noticeable that the highest probability of being satisfied with the household income (given the covariates) can be attributed to the SOEP respondents in 2001. In particular, this implies that the Germans are more likely to be contented than the British with a given amount of household income. In 2001, the difference in the probability between the Germans and the British is about 11 percentage points at the averages of the covariates. This is equivalent to a covariate contribution of about 10. One reason for the Germans' higher financial satisfaction may be partly seen in their contentment with the old currency, the deutschmark. Another explanation may be the country's prevailing conditions, in particular the extensive social security system that takes precautions, for example, with aged security. As a result, the Germans do not require private insurance to the same extent as the British-although the German system is currently under reform and moving towards a capital-funded system-and hence they can use a larger share of their income for present (or future) consumption.

The actually observed difference in contentment between the Germans and the British in 2001 is, however, clearly smaller as can be seen from the descriptive statistics above (cf. Section 3): It is a mere four percentage points. The reason for this may be the worse macroeconomic conditions for Germans. The unemployment rate as well as the rate of economic growth, which have a respective negative and positive impact on satisfaction with household 
Table 1

Estimation results

\begin{tabular}{|c|c|c|c|c|c|c|}
\hline \multirow[b]{2}{*}{ variable } & \multicolumn{2}{|c|}{ model 1} & \multicolumn{2}{|c|}{ model 2 (usage) } & \multicolumn{2}{|c|}{ model 3 (conversion) } \\
\hline & coefficient & s.e. & coefficient & s.e. & coefficient & s.e. \\
\hline year 2003 & 0.055 & 0.041 & 0.017 & 0.038 & 0.022 & 0.038 \\
\hline Germans & $0.467^{* *}$ & 0.063 & - & & - & \\
\hline Germans X year 2003 & $-0.405^{* *}$ & 0.051 & - & & - & \\
\hline Germans: difficulties in usage (yes) & - & & $0.174^{* *}$ & 0.054 & - & \\
\hline Germans: difficulties in usage (no) & - & & $0.533^{* *}$ & 0.052 & - & \\
\hline Germans: usage (yes) X year 2003 & - & & $-0.416^{* *}$ & 0.058 & - & \\
\hline Germans: usage (no) X year 2003 & - & & $-0.379^{* *}$ & 0.054 & - & \\
\hline Germans: difficulties in conversion (yes) & - & & - & & $0.129^{*}$ & 0.056 \\
\hline Germans: difficulties in conversion (no) & - & & - & & $0.519^{* *}$ & 0.051 \\
\hline Germans: conversion (yes) X year 2003 & - & & - & & $-0.441^{* *}$ & 0.062 \\
\hline Germans: conversion (no) X year 2003 & - & & - & & $-0.386^{* *}$ & 0.053 \\
\hline unemployment rate & $-0.062^{* *}$ & 0.006 & $-0.059^{* *}$ & 0.005 & $-0.059^{* *}$ & 0.005 \\
\hline inflation rate & -0.011 & 0.010 & $-0.017^{\dagger}$ & 0.009 & $-0.017^{\dagger}$ & 0.009 \\
\hline growth rate & 0.017 & 0.014 & 0.012 & 0.013 & 0.011 & 0.013 \\
\hline log of household income & $1.219^{* *}$ & 0.028 & $1.215^{* *}$ & 0.028 & $1.214^{* *}$ & 0.028 \\
\hline $\log$ of household size & $-0.757^{* *}$ & 0.038 & $-0.747^{* *}$ & 0.038 & $-0.742^{* *}$ & 0.038 \\
\hline female & 0.122 & 0.027 & 0.140 & 0.028 & 0.144 & 0.028 \\
\hline age & $-0.079^{* *}$ & 0.006 & $-0.081^{* *}$ & 0.006 & $-0.082^{* *}$ & 0.006 \\
\hline age squared & $0.001^{* *}$ & 0.000 & $0.001^{* *}$ & 0.000 & $0.001^{* *}$ & 0.000 \\
\hline heath status: bad & $-0.821^{* *}$ & 0.039 & $-0.801^{* *}$ & 0.039 & $-0.808^{* *}$ & 0.039 \\
\hline married (reference category: single) & $0.322^{* *}$ & 0.046 & $0.331^{* *}$ & 0.046 & $0.328^{* *}$ & 0.046 \\
\hline separated & $-0.700^{* *}$ & 0.100 & $-0.692^{* *}$ & 0.100 & $-0.695^{* *}$ & 0.100 \\
\hline widowed & $0.200^{* *}$ & 0.070 & $0.215^{* *}$ & 0.070 & $0.215^{* *}$ & 0.070 \\
\hline divorced & $-0.374^{* *}$ & 0.061 & $-0.374^{* *}$ & 0.061 & $-0.374^{* *}$ & 0.062 \\
\hline self-employed & -0.075 & 0.067 & -0.080 & 0.068 & -0.086 & 0.068 \\
\hline employee & $0.200^{* *}$ & 0.045 & $0.198^{* *}$ & 0.045 & $0.197^{* *}$ & 0.046 \\
\hline jobless & $-1.191^{* *}$ & 0.074 & $-1.194^{* *}$ & 0.074 & $-1.199^{* *}$ & 0.075 \\
\hline pensioner & 0.082 & 0.060 & 0.076 & 0.060 & 0.079 & 0.060 \\
\hline in training & 0.083 & 0.073 & 0.068 & 0.074 & 0.063 & 0.074 \\
\hline education low & $-0.189^{* *}$ & 0.033 & $-0.179^{* *}$ & 0.033 & $-0.174^{* *}$ & 0.033 \\
\hline education high & $0.314^{* *}$ & 0.039 & $0.316^{* *}$ & 0.039 & $0.314^{* *}$ & 0.039 \\
\hline constant & $-10.07^{* *}$ & 0.300 & $-9.925^{* *}$ & 0.299 & $-9.904^{* *}$ & 0.299 \\
\hline$\sigma_{\mu}^{2}$ & 0.361 & 0.030 & 0.360 & 0.030 & 0.360 & 0.030 \\
\hline$\sigma_{v}^{2}$ & 2.208 & 0.047 & 2.219 & 0.048 & 2.242 & 0.048 \\
\hline
\end{tabular}

Source: SOEP 2001-2003. BHPS 2001 and 2003. Macro variables from Eurostat and the Croner-Reward Group. Estimated with MLwiN using second-order penalized quasi likelihood (PQL). No. of individuals is 36,584. No. of observations is 60,422 . 


\section{Figure 4}

Predicted probability by year and population subgroup

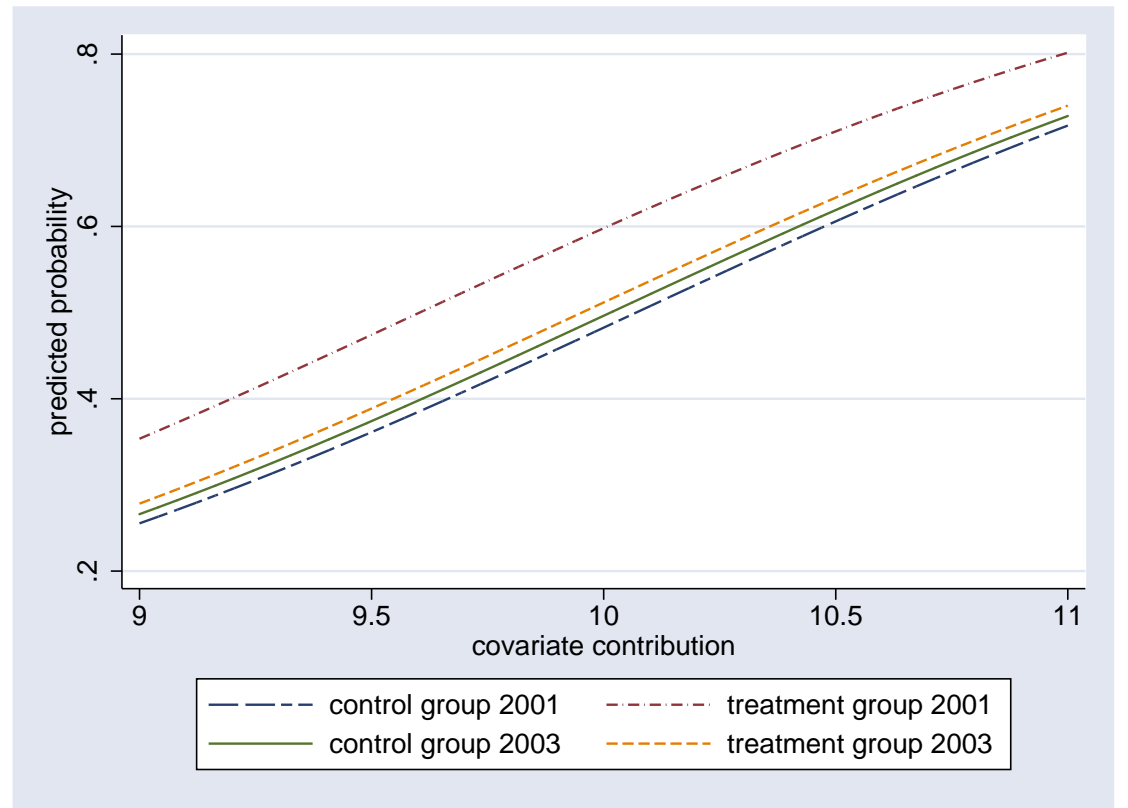

income, differ considerably between the countries. Both indicators exhibit comparatively unfavorable values for Germany.

After the introduction of the euro, there is a slump in financial satisfaction within the German population. Ceteris paribus, a representative individual's predicted probability decreases at approximately eight percentage points. In the United Kingdom, a reverse development can be observed for the same time period. Here a moderate rise in well-being of roughly 1.5 percentage points is found.

What impact of the total change in the predicted probabilities can be attributed to the introduction of the euro? The difference-in-differences estimator (DID-estimator) of the logit model is suitable for capturing the causal effect that is independent of the common time trend (which is not statistically significant) and the group-specific, time-invariant characteristics. The DID-estimator then provides a measure of the reduction in welfare that results from the policy intervention to be evaluated. On the basis of table 2, one can estimate a reduction of 9.7 percent in the predicted probability because of the introduction of the euro. The Delta method yields a standard error of the DID-estimator of 0.0214. The t-statistic is $-0.097 / 0.021=-4.62$ and the effect is, consequently, highly statistically significant. 


\section{Table 2}

\section{Predicted probabilities by year and population subgroup}

\begin{tabular}{|c|c|c|c|c|c|c|}
\hline \multirow{2}{*}{} & \multicolumn{2}{|c|}{ model 1 } & \multicolumn{2}{c|}{$\begin{array}{c}\text { model 3 } \\
\text { difficulties: yes }\end{array}$} & \multicolumn{2}{c|}{$\begin{array}{c}\text { model 3 } \\
\text { difficulties: no }\end{array}$} \\
\cline { 2 - 7 } & 2001 & 2003 & 2001 & 2003 & 2001 & 2003 \\
\hline control & 0.5337 & 0.5474 & 0.5735 & 0.5789 & 0.5735 & 0.5789 \\
\hline treatment & 0.6460 & 0.5627 & 0.6047 & 0.5016 & 0.6932 & 0.6111 \\
\hline
\end{tabular}

Note: Calculations for average values of covariates.

In 2002, the SOEP respondents were further questioned whether they had difficulties in using the new currency: "We would like to ask you how familiar you are personally with the new currency. Does the new cash, i.e., the new banknotes and coins, still provide you with great difficulty, some difficulty or no difficulties at all?" In a similar way, difficulties with the conversion of the old to the new currency were ascertained. The wording of the questionnaire was: "One now has to convert all previous DM amounts into euro amounts. Does this conversion still provide you with great difficulty, some difficulty or no difficulties at all?" (Schupp and Wagner 2007). The answers can be interpreted as proxy information about the respondents' financial ability, i.e., it provides information about how competent a person is in dealing with financial matters. People with a higher financial ability are expected to be more satisfied with their household income because they are able to use their resources more efficiently. Besides, they may feel less hampered by the introduction of the new currency as they have to bear lower costs of adjustment.

Applying the difference-in-differences estimation strategy again, the following part of the analysis makes use of this information and discusses whether the introduction of the euro had different effects on those persons with some or great difficulties compared with persons without difficulties regarding usage and conversion. As the proxy information is available only for 2002 it must be assumed that the financial ability is a time-invariant trait (at least for the short period under investigation). Consequently, a variable generated from the SOEP wave 19/S in 2002 was matched to the preceding and following waves. By this, the German subsample was divided in two partitions. We investigate whether the euro-induced loss in well-being differs in both subpartitions, that is, people with and without problems in converting the currency. 
The estimation results for the models identifying persons with some or great difficulties can be found in columns 4 to 7 in table 1 . In general, we find that there is an essential difference in the way the two (sub)groups judge their financial situation. The corresponding dummy variables indicate that Germans who report no difficulties show a clearly higher propensity to be satisfied with their household income than people who report such difficulties.

Turning attention to the causal effect of the introduction of the euro on these (sub)groups, the interaction effect indicates that, on the one hand, people experiencing no problems with the conversion from the old to the new currency show a reduction in contentment of 8.6 percentage points. On the other hand, persons who report difficulties in converting are characterized by even larger losses: the predicted probability of being satisfied is reduced by 10.9 percentage points. (The predicted probabilities are in table 2.) As the numbers are only valid for the sample averages, figure 5 shows the effects in dependence of a varying covariate contribution.

\section{Figure 5}

\section{Difference in differences}

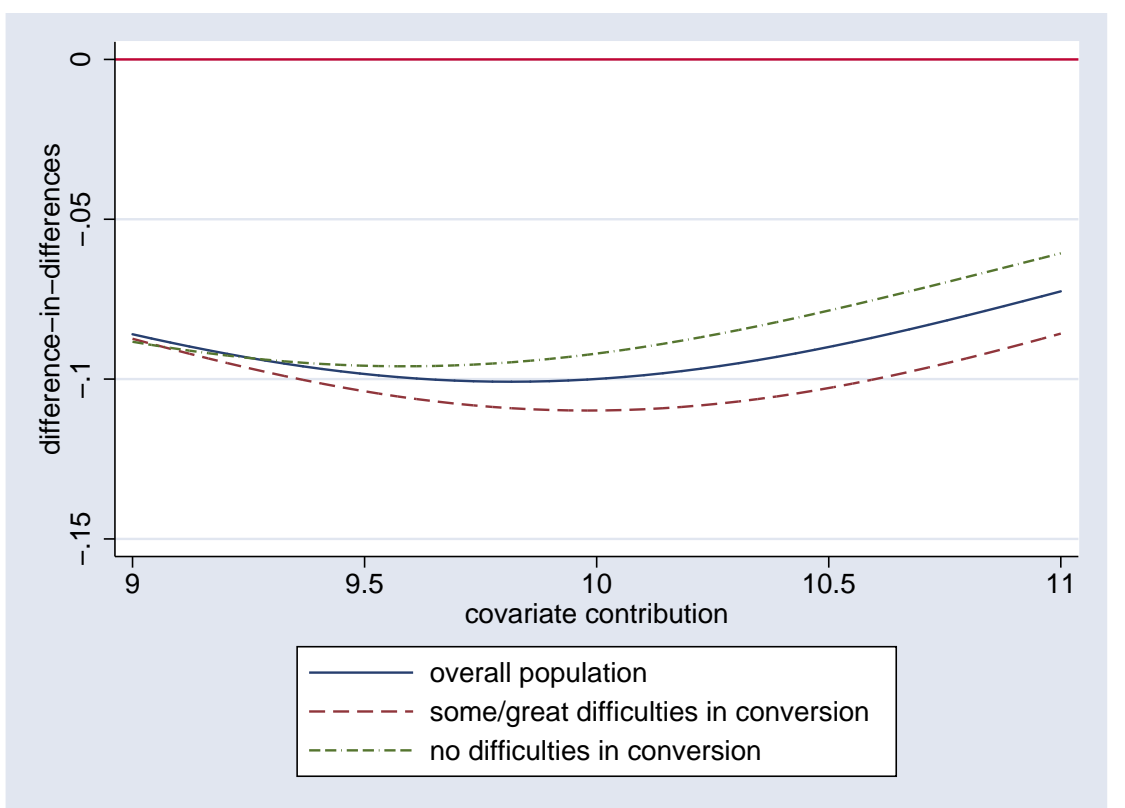

The difference in both numbers provides grounds for supposing that the persons who experience difficulties with the new currency are affected by a total loss in well-being that is larger than the loss for people without difficulties. ${ }^{3}$ However, at this stage we are not able to work out

\footnotetext{
${ }^{3}$ As we have not calculated standard errors, we cannot draw any conclusion on the significance of the difference. We do without a test for significance here because the issue is discussed in the next subsection in more detail.
} 
to what extent this difference is a consequence of the lack in financial ability and to what extent a stronger treatment effect in this (sub)group is responsible for the additional loss in well-being. This issue is discussed in the next subsection.

\subsection{The impact of the euro because of financial ability}

In the previous subsection, we found a difference in the losses in financial contentment with respect to whether a person experiences difficulties in converting the old to the new currency. Nevertheless, the difference is rather small and accounts only for a fifth of the total reduction. So the question to be discussed in this subsection is whether one can identify a significant difference between the two subgroups, i.e., between people with and without difficulties. If there is evidence for such a difference, distinguishing between the euro-induced and abilityinduced effects seems appropriate. The suitability of the dataset that combines information from the SOEP and BHPS is, however, limited because it uses information from 2001 and 2003. On the one hand, the BHPS does not provide data on contentment with household income for the year 2002, and as a consequence, this determines the definition of the sample. On the other hand, the difficulties in converting the currency are likely to be dissolved in 2003-after one year of everyday use-and cannot be observed in the data. For these reasons, we chose an alternative nonparametric matching approach that allows us to investigate the extent to which people who experienced problems in converting are hit by losses in financial contentment.

Table 3

Average treatment effect on the treated (ATT)

\begin{tabular}{|c||c|c|c|}
\hline \multicolumn{1}{|c||}{} & \multicolumn{2}{|c|}{ difficulties in conversion } & \multirow{2}{*}{ causal effect (ATT) } \\
\cline { 2 - 3 } & yes & no & \\
\hline 2001 to 2002 & -0.237 & -0.175 & $-0.062 * *$ \\
\hline 2001 to 2003 & -0.312 & -0.295 & -0.018 \\
\hline 2001 to 2004 & -0.462 & -0.425 & -0.037 \\
\hline
\end{tabular}

Note: Significance: $*<0.1 ; * *<0.05 ; * * *<0.01$. 
Table 3 shows the calculations of the average treatment effect on the treated (ATT) for the three years 2002, 2003 and 2004 that followed the introduction of euro cash. ${ }^{4}$ The numbers refer to the reduction of financial satisfaction as measured on an 11-point scale. As can be seen in the first year of the euro, 2002, there is a reduction in financial well-being in both the group of people with and without difficulties in conversion of 0.237 points and 0.175 respectively. Because the loss is higher for persons with difficulties, this shows a significant causal effect of financial abilities on financial well-being of -0.062 . Considering the finding of the previous section that there was a clear euro-induced reduction in contentment, people with a lower financial ability had to bear an additional loss compared with those who were more able. However, the extra costs are firstly of a rather small magnitude. Secondly, this effect is only significant in the first year of the euro's introduction. Even though the reduction in well-being after the euro introduction generally deepens with the time elapsed, this applies to persons with and without difficulties alike. Therefore, we conclude that persons overcame their difficulties after they had been using the new currency for one year.

\section{Conclusion}

To the best of our knowledge, this paper examines for the first time the real effects on individual well-being of the introduction of the euro. We investigate the causal effect of the changeover to the new currency for Germans. Using a dataset that merges information from the BHPS and the SOEP, we are able to construct a treatment group that is affected by the euro, the Germans, and a control group that is not affected, the British. This allows us to draw conclusions from the application of a difference-in-differences approach-a method appropriate for evaluating the impacts of a policy intervention.

The empirical analysis indicates the substantial impact of the introduction of the euro on financial satisfaction. The estimation results suggest a reduction in the predicted probability that a person is satisfied with his/her household income of 9.7 percentage points. This is a rather drastic decline when the compensating income variation is considered: an increase in income

\footnotetext{
${ }^{4}$ For the calculations, we used the Stata ado-file psmatch2 by Leuven and Sianesi (2003), version 3.1.1. The variables used to construct the propensity score can be found in table 6 in the appendix. See also figure 6 for the common support.
} 
of approximately one-third—on the basis of the estimation results, we calculated $37 \% 5$-is required to compensate a person for the severe loss in well-being because of the introduction of the euro. We do not, of course, propose a real income compensation. Instead, we argue that people suffer a decline in contentment $a$ s if they required an increase in income by one-third.

The mode of action of the euro inducing the slump in financial satisfaction is suspected to evolve for a number of reasons. According to a large number of earlier studies (cf. Section 2 for an overview), the perceived price inflation led to a considerable overestimation of real prices, and hence the households' decisions on consumption were no longer maximizing their wellbeing. The aforementioned studies estimate the perceived inflation to be between $3.2 \%$ and $5.7 \%$ (cf. Brachinger 2006). Furthermore, money illusion resulting from the decline in nominal household income may have the consequence that the budget constraint was misjudged. The shift of the budget constraint towards the origin of the space of consumption possibilities causes an additional reduction in satisfaction with the household income. Finally, the changeover and adjustment to the new currency triggered additional costs for people.

In the context of the latter point, the analysis brought out the fact that an individual's financial ability has an impact on the severity of the loss of well-being because of the euro. Persons who experience difficulties in using and/or in converting the euro have to bear higher costs in terms of losses in well-being, whereas people without such difficulties seem to be affected less seriously. Therefore, we can differentiate between euro-induced and ability-induced losses in welfare because of the changeover to the new currency. However, the additional causal effects for the persons with a lower financial ability are of a rather small magnitude, as we established using a nonparametric DID estimator. In addition, the difficulties in converting appear to have been overcome within one year following the introduction of euro cash.

Despite the quite tiny impact of financial ability, policy makers concerned with future euro candidates would be well advised to make efforts in the field of financial education in order to keep the losses in well-being as small as possible. As the Germans were familiar with the DM because of daily use for many decades, with cash transactions being the most natural thing in the world, the introduction of euro cash in 2002 interrupted the continuity of the medium. However,

\footnotetext{
${ }^{5}$ This is calculated on the basis of the marginal effect of an increase in the logarithm of household income: $\partial E(y \mid$ euro $=1$, time $=1, \overline{\mathbf{x}}) / \partial \ln ($ HH income $)=0.29$. Apparently, a change of $\ln ($ HH income $)$ by 0.33 results in a change in the predicted probability of 0.097.
} 
the major causal mechanism appears to lead to a negative view toward the new currency that cannot be attributed to financial ability. 


\section{References}

Ai, C. and Norton, E. C. (2003). Interaction terms in logit and probit models, Economics Letters 80(1): $123-129$.

Bergemann, A., Fitzenberger, B. and Speckesser, S. (2005). Evaluating the dynamic employment effects of training programs in East Germany using conditional difference-indifferences, IZA Discussion Papers 1848, Institute for the Study of Labor (IZA).

Blundell, R. and Costa Dias, M. (2002). Alternative approaches to evaluation in empirical microeconomics, CeMMAP Working Papers CWP10/02, Centre for Microdata Methods and Practice, Institute for Fiscal Studies.

Brachinger, H. W. (2006). Euro or "teuro"?: The euro-induced perceived inflation in Germany, DQE Working Papers 5, Department of Quantitative Economics, University of Freiburg/Fribourg Switzerland.

Brandstätter, E. and Brandstätter, H. (1996). What's money worth? Determinants of the subjective value of money, Journal of Economic Psychology 17(4): 443-464.

Burkhauser, R. V., Butrica, B. A., Daly, M. C. and Lillard, D. R. (2000). The cross-national equivalent file: A product of cross-national research, Technical report, Cornell University.

Clark, A. E. and Oswald, A. J. (1994). Unhappiness and unemployment, Economic Journal 104(424): 648-59.

Deutsche Bundesbank (2002). Die Verbraucherpreise beim Übergang von der D-Mark auf den Euro, Monatsbericht Juli 2002 54(7): 15-24.

Dittmann, J. (2005). Forschungsbericht über die prototypische Verknüpfung des SOEP mit 'Medien Tenor'-Daten, Research Notes 6, DIW Berlin, German Institute for Economic Research, Berlin.

European Commission (2006a). Adopting the euro: Economic and communication challenges, European Economy (2): 6-7.

European Commission (2006b). The joint harmonised EU programme of business and consumer surveys. User guide, Technical report, European Commission.

URL: http://ec.europa.eu/economy_finance/indicators/business_consumer_surveys/ userguide_en.pdf

Fisher, I. (1928). The money illusion, Adelphi, New York.

Fluch, M. and Stix, H. (2005). Perceived inflation in Austria-extent, explanations, effects, Monetary Policy \& the Economy (3): 22-47.

Frey, B. S. and Stutzer, A. (2000). Happiness, economy and institutions, Economic Journal 110(466): 918-38.

Frey, B. S. and Stutzer, A. (2002a). Happiness and economics. How the economy and institutions affect well-being, Princeton Univ. Press, Princeton. 
Frey, B. S. and Stutzer, A. (2002b). What can economists learn from happiness research?, Journal of Economic Literature 40(2): 402-435.

Gibbons, R. D. and Hedeker, D. (1997). Random effects probit and logistic regression models for three-level data, Biometrics 53(4): 1527-1537.

Guo, G. and Zhao, H. (2000). Multilevel modeling for binary data, Annual Review of Sociology 26: $441-462$.

Haisken-DeNew, J. P. (2005). SOEP Menu: A menu-driven Stata/SE interface for accessing the German Socio-Economic Panel, mimeo.

URL: $h t t p: / / w w w . s o e p m e n u . d e$

Haisken-DeNew, J. P. and Frick, J. R. (2005). DTC. Companion to the German Socio-Economic Panel Study (GSOEP).

URL: http://www.diw.de/english/sop/service/dtc/

Heckman, J., Ichimura, H., Smith, J. and Todd, P. (1998). Characterizing selection bias using experimental data, Econometrica 66(5): 1017-1098.

Isengard, B. and Schneider, T. (2006). Attitudes towards the euro: An empirical study based on the German Socio-Economic Panel (SOEP), Social Indicators Research .

URL: http://www.springerlink.com/content/l33416858751lr78

Layard, R. (2005). Happiness: Lessons from a new science, Allen Lane, London.

Leuven, E. and Sianesi, B. (2003). Psmatch2: Stata module to perform full Mahalanobis and propensity score matching, common support graphing, and covariate imbalance testing, Statistical Software Components, Boston College Department of Economics.

Mitchell, M. N. and Chen, X. (2005). Visualizing main effects and interactions for binary logit models, Stata Journal 5(1): 64-82.

Moulton, B. R. (1990). An illustration of a pitfall in estimating the effects of aggregate variables on micro unit, The Review of Economics and Statistics 72(2): 334-38.

Norton, E. C., Wang, H. and Ai, C. (2004). Computing interaction effects and standard errors in logit and probit models, Stata Journal 4(2): 154-167.

Ostaszewski, P., Green, L. and Myerson, J. (1998). Effets of inflation on subjective value of delayed and probabilistic rewards, Psychonomic Bulletin and Review 5(2): 324-333.

Rosenbaum, P. R. and Rubin, D. B. (1983). The central role of the propensity score in observational studies for causal effects, Biometrika 70(1): 41-55.

Rosenbaum, P. R. and Rubin, D. B. (1985). Constructing a control group using multivariate matched sampling methods that incorporate the propensity score, The American Statistican 39(1): 33-38.

Schupp, J. and Wagner, G. G. (2007). New concepts and new questions in the German SocioEconomic Panel Study (SOEP), Schmollers Jahrbuch 127(1). forthcoming. 
Schwarze, J. (2003). Using panel data on income satisfaction to estimate equivalence scale elasticity, Review of Income and Wealth 49(3): 359-372.

Shafir, E., Diamond, P. and Tversky, A. (1997). Money illusion, The Quarterly Journal of Economics 112(2): 341-74.

Skrondal, A. and Rabe-Hasketh, S. (2004). Generalized Latent Variable Modeling, Interdisciplinary Statistics Series, Chapman \& Hall, Boca-Raton.

Smith, J. A. and Todd, P. E. (2005). Does matching overcome LaLonde's critique of nonexperimental estimators?, Journal of Econometrics 125(1-2): 305-353.

Stix, H. (2005). Perceived inflation and the euro: Why high? Why persistent?, mimeo. URL: $h t t p: / / w w w . e e a-e s e m . c o m / E E A-E S E M / 2006 / p r o g / v i e w p a p e r . a s p ?$ pid=2347

Taylor, M. F., Brice, J., Buck, N. and Prentice-Lane, E. (2006). British household panel survey user manual volume a: Introduction, technical report and appendices, Technical report, University of Essex, Colchester.

Winkelmann, L. and Winkelmann, R. (1998). Why are the unemployed so unhappy? Evidence from panel data, Economica 65(257): 1-15. 


\section{A Descriptive statistics}

Table 4

Descriptive statistics for SOEP-subsample

\begin{tabular}{|c|c|c|c|c|}
\hline subsample: SOEP & mean & s.e. & $\min$ & $\max$. \\
\hline satisfied with $\mathrm{HH}$ income & 0.549 & 0.498 & 0 & 1 \\
\hline year 2003 & 0.478 & 0.500 & 0 & 1 \\
\hline unemployment rate & 10.482 & 4.716 & 4.9 & 20.5 \\
\hline inflation rate & 1.551 & 0.515 & 0.293 & 2.3 \\
\hline growth rate & 0.343 & 0.950 & -1.7 & 2.5 \\
\hline log of $\mathrm{HH}$ income & 10.242 & 0.592 & 3.131 & 12.952 \\
\hline $\log$ of $\mathrm{HH}$ size & 0.909 & 0.488 & 0 & 2.565 \\
\hline age & 47.416 & 16.883 & 17 & 100 \\
\hline age (squared) & 2533.3 & 1703.9 & 289 & 10000 \\
\hline health status: bad & 0.132 & 0.338 & 0 & 1 \\
\hline single & 0.210 & 0.407 & 0 & 1 \\
\hline married & 0.635 & 0.481 & 0 & 1 \\
\hline separated & 0.016 & 0.127 & 0 & 1 \\
\hline divorced & 0.072 & 0.259 & 0 & 1 \\
\hline widowed & 0.067 & 0.249 & 0 & 1 \\
\hline self-employed & 0.055 & 0.228 & 0 & 1 \\
\hline employee & 0.496 & 0.500 & 0 & 1 \\
\hline jobless & 0.065 & 0.246 & 0 & 1 \\
\hline pensioner & 0.240 & 0.427 & 0 & 1 \\
\hline in training & 0.058 & 0.234 & 0 & 1 \\
\hline education low & 0.203 & 0.402 & 0 & 1 \\
\hline education middle & 0.604 & 0.489 & 0 & 1 \\
\hline education high & 0.193 & 0.395 & 0 & 1 \\
\hline female & 0.520 & 0.500 & 0 & 1 \\
\hline
\end{tabular}

Source: SOEP 2001 and 2003. $n=22111, n T=39679$.

Table 5

Descriptive statistics for BHPS-subsample

\begin{tabular}{|c|c|c|c|c|}
\hline subsample: BHPS & mean & s.e. & $\min$. & $\max$. \\
\hline satisfied with $\mathrm{HH}$ income & 0.557 & 0.497 & 0 & 1 \\
\hline year 2003 & 0.575 & 0.494 & 0 & 1 \\
\hline unemployment rate & 5.386 & 1.336 & 3.4 & 9.4 \\
\hline inflation rate & 3.118 & 2.444 & 0 & 13.4 \\
\hline growth rate & 2.508 & 1.095 & -1.4 & 7.1 \\
\hline $\log$ of $\mathrm{HH}$ income & 10.218 & 0.712 & -0.125 & 12.82 \\
\hline $\log$ of $\mathrm{HH}$ size & 0.887 & 0.516 & 0 & 2.303 \\
\hline age & 46.473 & 18.495 & 16 & 99 \\
\hline age (squared) & 2501.8 & 1859.9 & 256 & 9801 \\
\hline health status: bad & 0.082 & 0.275 & 0 & 1 \\
\hline single & 0.263 & 0.440 & 0 & 1 \\
\hline married & 0.548 & 0.498 & 0 & 1 \\
\hline separated & 0.021 & 0.145 & 0 & 1 \\
\hline divorced & 0.085 & 0.278 & 0 & 1 \\
\hline widowed & 0.084 & 0.277 & 0 & 1 \\
\hline self-employed & 0.068 & 0.252 & 0 & 1 \\
\hline employee & 0.502 & 0.500 & 0 & 1 \\
\hline jobless & 0.032 & 0.177 & 0 & 1 \\
\hline pensioner & 0.226 & 0.418 & 0 & 1 \\
\hline in training & 0.046 & 0.209 & 0 & 1 \\
\hline education low & 0.516 & 0.500 & 0 & 1 \\
\hline education middle & 0.360 & 0.480 & 0 & 1 \\
\hline education high & 0.124 & 0.329 & 0 & 1 \\
\hline female & 0.532 & 0.499 & 0 & 1 \\
\hline
\end{tabular}

Source: BHPS 2001 and 2003. $n=14473, n T=20743$. 


\section{B Balancing the means of covariates}

In table 6 below, we list the covariates of "difficulties" and "well-being" that are included in the construction of propensity scores. Before matching, the means of the covariates in the groups of persons with and without difficulties differ from each other. For example, before matching, persons with difficulties had an average household income of about 30000 euro and those without difficulties have incomes of 33000. A $t$-test shows that this difference is significant and the so-called standardized bias (sb) is high with $-16,7 \%$. The sb is computed as (cf. Rosenbaum and Rubin 1985)

$$
s b=\frac{\bar{x}_{e=0}-\bar{x}_{e=1}}{\sqrt{\left(s_{e=0}^{2}+s_{e=1}^{2}\right) 0,5}} \cdot 100
$$

where $\bar{x}_{e=0}-\bar{x}_{e=1}$ is the difference in means of covariate $x$ in the sample of treated and controls, and $s^{2}$ are the respective variances. When successful, matching leads to a subsample of treated and controls where the t-tests are insignificant and biases tend towards zero. Consequently, after matching, household incomes in both groups are about 30000 euro, leaving almost no bias and leading to an insignificant t-test. The bias is almost always reduced extensively, with the exception of the dummy variable trained w-collar worker with simple tasks.

\section{Table 6}

\section{Balancing the means of covariates}

\begin{tabular}{|c|c|c|c|c|c|c|c|}
\hline \multirow[b]{2}{*}{ variable } & \multirow[t]{2}{*}{ match } & \multicolumn{2}{|c|}{ difficulties in conversion } & \multirow[b]{2}{*}{$\begin{array}{r}\text { standardized } \\
\text { bias (sb) }\end{array}$} & \multirow[b]{2}{*}{$\begin{array}{r}\text { bias } \\
\text { reduction }\end{array}$} & \multirow[b]{2}{*}{$\mathbf{t}$} & \multirow[b]{2}{*}{$\mathbf{p}>\mathbf{t}$} \\
\hline & & yes & no & & & & \\
\hline \multirow[t]{2}{*}{ age in 2001} & before & 47.499 & 46.243 & 7.4 & & 4.87 & 0 \\
\hline & after & 47.404 & 47.056 & 2 & 72.3 & 1.13 & 0.26 \\
\hline \multirow[t]{2}{*}{ not born in Germany } & before & 0.1685 & 0.1086 & 17.4 & & 11.67 & 0 \\
\hline & after & 0.1582 & 0.1568 & 0.4 & 97.6 & 0.22 & 0.825 \\
\hline \multirow[t]{2}{*}{$\operatorname{sex}$} & before & 0.599 & 0.4803 & 24 & & 15.54 & 0 \\
\hline & after & 0.5937 & 0.6052 & -2.3 & 90.3 & -1.31 & 0.19 \\
\hline \multirow[t]{2}{*}{ household income (post taxes) } & before & 29930 & 32993 & -16.7 & & -10.58 & 0 \\
\hline & after & 30023 & 30024 & 0 & 99.9 & -0.01 & 0.996 \\
\hline \multicolumn{8}{|l|}{ health status } \\
\hline \multirow{2}{*}{++} & before & 0.0808 & 0.12019 & -13.1 & & -8.3 & 0 \\
\hline & after & 0.082 & 0.08389 & -0.6 & 95.2 & -0.38 & 0.701 \\
\hline \multirow[t]{2}{*}{+} & before & 0.36998 & 0.42085 & -10.4 & & -6.75 & 0 \\
\hline & after & 0.3738 & 0.3706 & 0.7 & 93.7 & 0.37 & 0.711 \\
\hline \multirow[t]{2}{*}{$\mathrm{o}$} & before & 0.34509 & 0.32245 & 4.8 & & 3.13 & 0.002 \\
\hline & after & 0.34673 & 0.34716 & -0.1 & 98.1 & -0.05 & 0.96 \\
\hline \multirow[t]{2}{*}{-} & before & 0.15845 & 0.111 & 13.9 & & 9.29 & 0 \\
\hline & after & 0.15343 & 0.15615 & -0.8 & 94.3 & -0.42 & 0.674 \\
\hline \multirow[t]{2}{*}{-} & before & 0.04568 & 0.02551 & 10.9 & & 7.43 & 0 \\
\hline & after & 0.04404 & 0.0422 & 1 & 90.9 & 0.51 & 0.612 \\
\hline \multicolumn{8}{|l|}{ state } \\
\hline \multirow[t]{2}{*}{ Berlin } & before & 0.02032 & 0.0187 & 1.2 & & 0.77 & 0.443 \\
\hline & after & 0.02018 & 0.02282 & -1.9 & -63.1 & -1.02 & 0.309 \\
\hline \multirow[t]{2}{*}{ Schleswig-Holstein } & before & 0.02788 & 0.03082 & $\begin{array}{l}-1.7 \\
\end{array}$ & & -1.12 & 0.261 \\
\hline & after & 0.02819 & 0.03008 & -1.1 & 35.6 & -0.63 & 0.529 \\
\hline \multirow[t]{2}{*}{ Hamburg } & before & 0.00992 & 0.01386 & -3.6 & & -2.3 & 0.021 \\
\hline & after & 0.00993 & 0.0094 & 0.5 & 86.5 & 0.3 & 0.76 \\
\hline \multirow[t]{2}{*}{ Lower Saxony } & before & 0.08616 & 0.08707 & -0.3 & & -0.21 & 0.833 \\
\hline & after & 0.08648 & 0.08598 & 0.2 & 44.6 & 0.1 & 0.92 \\
\hline \multirow[t]{2}{*}{ Bremen } & before & 0.0041 & 0.00903 & -6.1 & & -3.75 & 0 \\
\hline & after & 0.004 & 0.00304 & 1.2 & 80.5 & 0.91 & 0.365 \\
\hline \multirow{2}{*}{ North Rhine-Westphalia } & before & 0.20129 & 0.21597 & -3.6 & & -2.34 & 0.019 \\
\hline & after & 0.20099 & 0.1972 & 0.9 & 74.2 & 0.53 & 0.596 \\
\hline
\end{tabular}




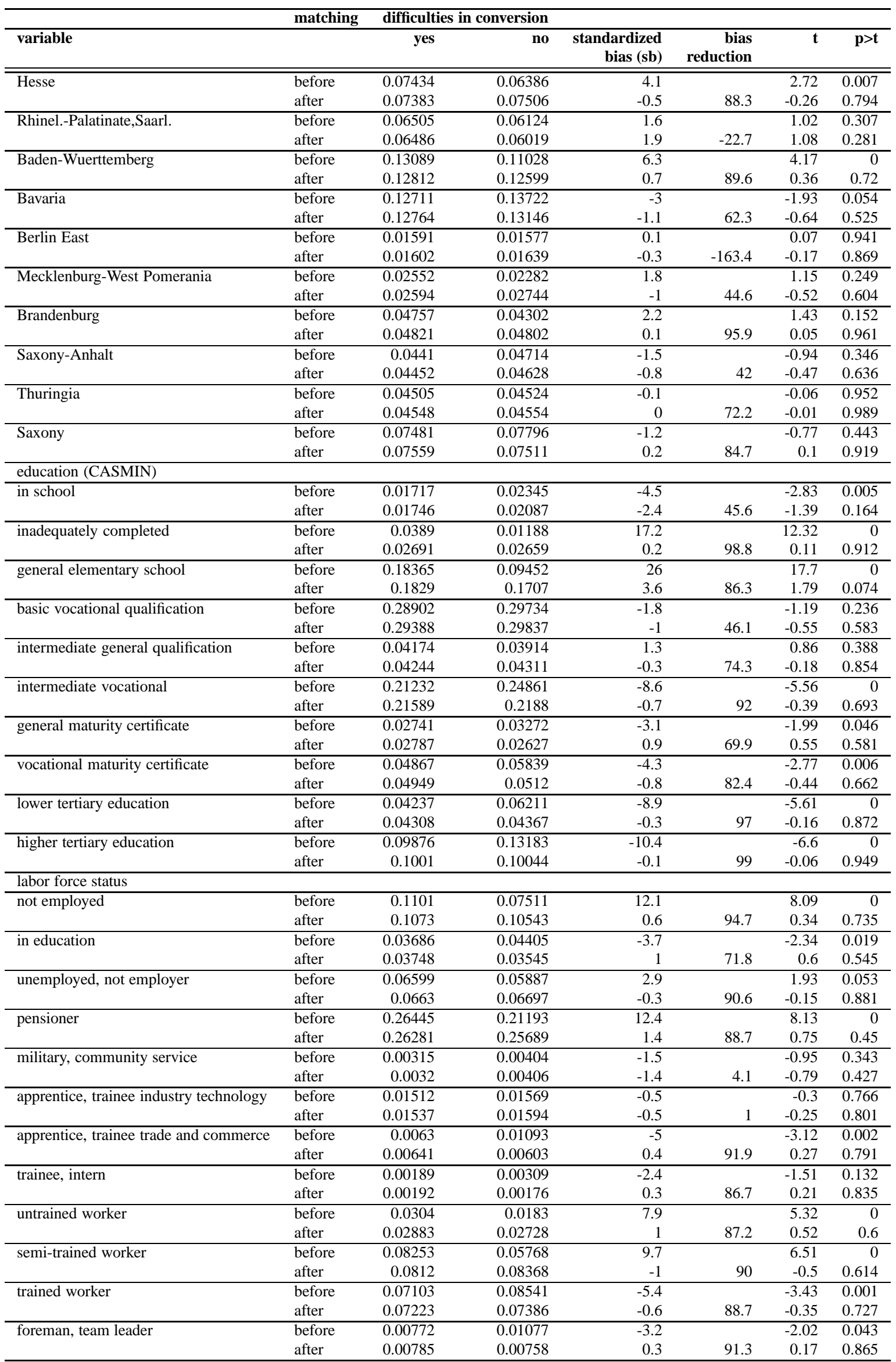




\begin{tabular}{|c|c|c|c|c|c|c|c|}
\hline \multirow[b]{2}{*}{ variable } & \multirow[t]{2}{*}{ matching } & \multicolumn{2}{|c|}{ difficulties in conversion } & \multirow[b]{2}{*}{$\begin{array}{r}\text { standardized } \\
\text { bias (sb) } \\
\end{array}$} & \multirow[b]{2}{*}{$\begin{array}{r}\text { bias } \\
\text { reduction }\end{array}$} & \multirow[b]{2}{*}{$\mathbf{t}$} & \multirow[b]{2}{*}{$\bar{p}>\mathbf{t}$} \\
\hline & & yes & no & & & & \\
\hline \multirow[t]{2}{*}{ foreman } & before & $\overline{0.0052}$ & 0.00515 & $\overline{0.1}$ & & $\overline{0.04}$ & 0.965 \\
\hline & after & 0.00529 & 0.00507 & 0.3 & -345.5 & 0.17 & 0.868 \\
\hline \multirow[t]{2}{*}{ self-employed farmer no coworkers } & before & 0.00189 & 0.00151 & 0.9 & & 0.62 & 0.536 \\
\hline & after & 0.00192 & 0.00198 & -0.1 & 86.1 & -0.07 & 0.946 \\
\hline \multirow[t]{2}{*}{ self-employed farmer le 9 coworkers } & before & 0.0011 & 0.00103 & 0.2 & & 0.15 & 0.884 \\
\hline & after & 0.00112 & 0.00117 & -0.2 & 26.5 & -0.09 & 0.93 \\
\hline \multirow[t]{2}{*}{ self-employed farmer gt 9 coworkers } & before & 0.00016 & 0.00016 & 0 & & 0 & 0.996 \\
\hline & after & 0.00016 & 0.00021 & -0.4 & -5529.1 & -0.22 & 0.827 \\
\hline \multirow[t]{2}{*}{ free-lance professional, no coworkers } & before & 0.0052 & 0.00856 & -4.1 & & -2.54 & 0.011 \\
\hline & after & 0.00529 & 0.00545 & -0.2 & 95.2 & -0.12 & 0.903 \\
\hline \multirow[t]{2}{*}{ free-lance professional, le 9 coworkers } & before & 0.00362 & 0.00491 & -2 & & -1.25 & 0.21 \\
\hline & after & 0.00368 & 0.00374 & -0.1 & 95.9 & -0.05 & 0.961 \\
\hline \multirow[t]{2}{*}{ free-lance professional, gt 9 coworkers } & before & 0.00016 & 0.00119 & -4 & & -2.31 & 0.021 \\
\hline & after & 0 & 0 & 0 & 100 & . & . \\
\hline \multirow[t]{2}{*}{ other self-employed no coworkers } & before & 0.01229 & 0.01941 & -5.7 & & -3.58 & $\overline{0}$ \\
\hline & after & 0.01249 & 0.01255 & 0 & 99.3 & -0.03 & 0.979 \\
\hline \multirow[t]{2}{*}{ other self-employed le 9 coworkers } & before & 0.0104 & 0.01989 & -7.8 & & -4.81 & $\overline{0}$ \\
\hline & after & 0.01041 & 0.01132 & -0.7 & 90.4 & -0.49 & 0.625 \\
\hline \multirow[t]{2}{*}{ other self-employed gt 9 coworkers } & before & 0.00158 & 0.00372 & -4.2 & & -2.55 & 0.011 \\
\hline & after & 0.0016 & 0.00155 & 0.1 & 97.5 & 0.08 & 0.94 \\
\hline \multirow[t]{2}{*}{ help in family business } & before & 0.00236 & 0.00293 & -1.1 & & -0.71 & 0.48 \\
\hline & after & 0.0024 & 0.00251 & -0.2 & 81.2 & -0.12 & 0.904 \\
\hline \multirow[t]{2}{*}{ foreman } & before & 0.00347 & 0.00436 & -1.4 & & -0.91 & 0.362 \\
\hline & after & 0.00352 & 0.00347 & 0.1 & 94 & 0.05 & 0.96 \\
\hline \multirow{2}{*}{$\begin{array}{l}\text { untrained w-collar worker } \\
\text { with simple tasks }\end{array}$} & before & 0.02331 & 0.02361 & -0.2 & & -0.13 & 0.898 \\
\hline & after & 0.0237 & 0.02704 & -2.2 & -1016.6 & -1.19 & 0.236 \\
\hline \multirow{2}{*}{$\begin{array}{l}\text { trained w-collar worker } \\
\text { with simple tasks }\end{array}$} & before & 0.04016 & 0.04136 & -0.6 & & -0.39 & 0.696 \\
\hline & after & 0.04084 & 0.04797 & -3.6 & -497.6 & -1.93 & 0.053 \\
\hline \multirow[t]{2}{*}{ qualified professional } & before & 0.11167 & 0.13619 & -7.4 & & -4.77 & $\overline{0}$ \\
\hline & after & 0.11355 & 0.11387 & -0.1 & 98.7 & -0.06 & 0.955 \\
\hline h. qualified professional & before & 0.0452 & 0.08018 & -14.5 & & -9.02 & $\overline{0}$ \\
\hline & after & 0.0458 & 0.0434 & 1 & 93.1 & 0.65 & 0.516 \\
\hline managerial & before & 0.00284 & 0.00903 & -8.1 & & -4.85 & $\overline{0}$ \\
\hline & after & 0.00288 & 0.00203 & 1.1 & 86.2 & 0.96 & 0.335 \\
\hline low-level civil service & before & 0.00079 & 0.00103 & -0.8 & & -0.51 & 0.609 \\
\hline & after & 0.0008 & 0.00069 & 0.4 & 56 & 0.22 & 0.827 \\
\hline middle-level civil service & before & 0.01181 & 0.01173 & 0.1 & & 0.05 & 0.958 \\
\hline & after & 0.01201 & 0.00972 & 2.1 & -2528.7 & 1.24 & 0.216 \\
\hline high-level civil service & before & 0.01386 & 0.01577 & -1.6 & & -1.01 & 0.31 \\
\hline & after & 0.01409 & 0.0134 & 0.6 & 63.6 & 0.33 & 0.739 \\
\hline executive civil service & before & 0.00583 & 0.00959 & -4.3 & & -2.69 & 0.007 \\
\hline & after & 0.00593 & 0.00603 & -0.1 & 97.2 & -0.08 & 0.938 \\
\hline employed without stib info & before & 0.00158 & 0.00285 & -2.7 & & -1.69 & 0.091 \\
\hline & after & 0.0016 & 0.00192 & -0.7 & 74.9 & -0.43 & 0.67 \\
\hline
\end{tabular}

Source: SOEP 2001-2004. 


\section{Common support}

Matching imposes the so-called common support condition. This means that when there is no observation $j$ with a similar PS to a observation $i$ in the treatment group, this observation will be excluded from the analysis. Equivalently, all observations $i$ with no similar observation $j$ to be found in the control group will not be used to compute the causal effect. As the figure below shows, there is sufficient common support, and only a few persons of the treated had to be excluded.

\section{Figure 6}

\section{Common support}

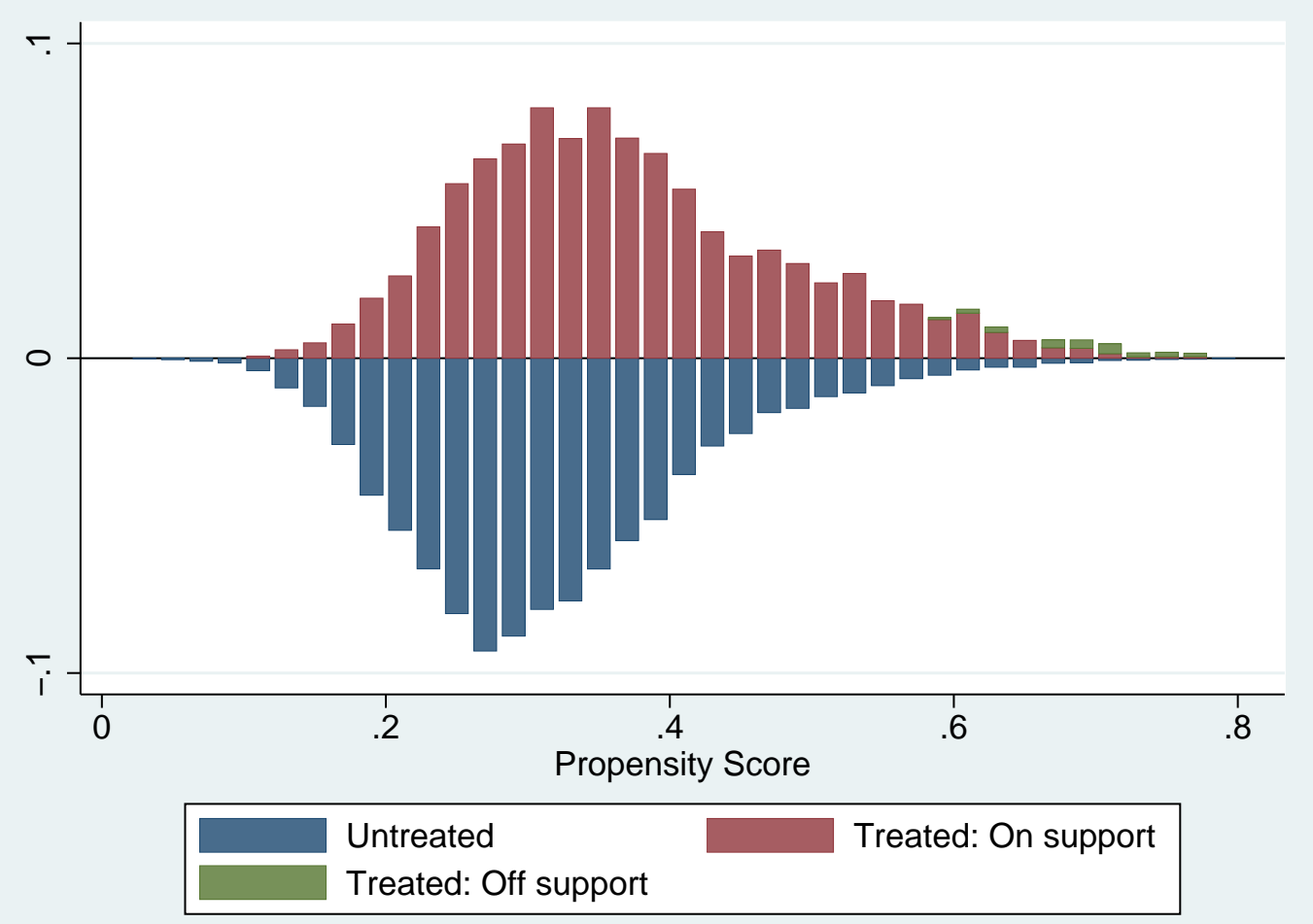

Source: SOEP 2001-2004. 